\title{
Study on Application of Tio2 Photocatalytic Materials in Purification of Highway Tunnel Tail Gas
}

\author{
Zhiqiang Liu ${ }^{1}$, Haifeng Jiang ${ }^{1}$, Minmin Yuan ${ }^{1}$ \\ ${ }^{1}$ Research institute of highway ministry of transport, Beijing, China
}

\begin{abstract}
In recent years, with the continuous expansion of the scale of highway tunnels in China, the problem of tail gas pollution in highway tunnels has become increasingly prominent. The tunnel is a long and narrow space, which makes air pollutants easy to accumulate and difficult to diffuse. In this paper, the present situation and application scenarios of $\mathrm{TiO} 2$ photocatalytic materials in the purification technology of highway tunnel exhaust gas are studied and analyzed, and the nano $\mathrm{TiO} 2$ photocatalytic materials which can be applied to highway tunnels, corresponding highway stations and their affiliated facilities are put forward, so as to greatly degrade automobile exhaust gas, atmospheric chemical pollution and environmental biological pollution.
\end{abstract}

\section{Introduction}

With the increasing number of large highway tunnels in China year by year, and with the increasing automobile retain number in China, the traffic volume in tunnels gradually increases. Due to the poor ventilation of the tunnel caused by its semi-closed tubular structure, the concentration of pollutants in the tunnel is significantly higher than that outside the tunnel. These pollutants contain a large number of gases which seriously endanger the health of drivers and passengers, such as $\mathrm{CO}$, NOx and HC. At present, physical methods, such as installing ventilation equipment, are mainly used in tunnels to disperse the automobile exhaust in tunnels, which doesn't has a substantial degradation effect by chemical removal methods. Moreover, such ventilation and air exchange methods in tunnels has huge investment, high operating costs and poor environmental benefits, and causes secondary noise pollution in tunnels at the same time. Therefore, it is of great significance to explore the air pollutant purification measures with good economic and environmental benefits for improving the driving environment of the tunnel and improving the tunnel operation safety.

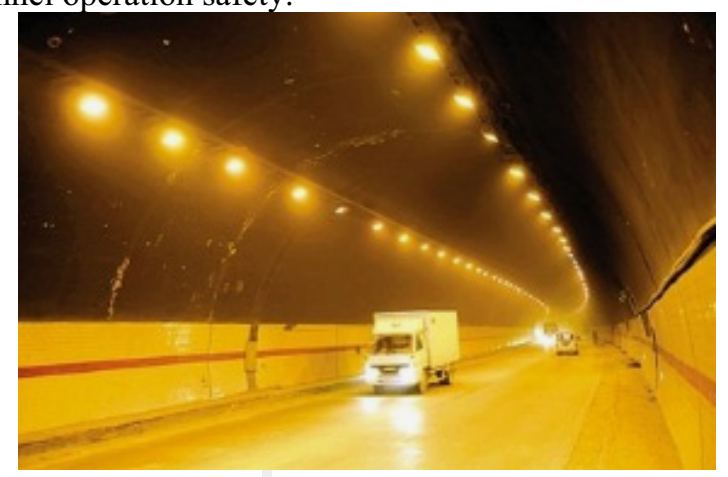

Figure 1 Tunnel exhaust pollution

\section{Analysis of current technical situation}

The scientific research and technological development of building surface and pavement materials with exhaust decomposition function is a new industry and innovation for the control and treatment of motor vehicle exhaust pollution under the new situation. Under the condition of light irradiation, $\mathrm{TiO} 2$ can decompose $\mathrm{CO}, \mathrm{HC}$ and $\mathrm{NOx}$ in automobile exhaust into carbonate and nitrate, so as to realize the function of decomposing automobile exhaust. However, Nano-TiO2 particles have some defects. It has wide band gap, low utilization rate of ordinary light source generated by lighting equipment in tunnel and high recombination rate of photo-generated electron-hole pairs, which greatly affects its photocatalytic efficiency and restricts the application of photocatalyst in tunnel pavement. At present, the application research of photocatalytic materials is pioneered by Western developed countries, including Japan, Britain, Italy and other developed countries. It has achieved certain research results and has been gradually promoted and applied in major western cities with severe industrial pollution. Germany, France and the United States have also made great progress in product development and engineering application. At present, the application to large-scale road surface construction is still in the exploratory stage. In some related studies in foreign countries, the degradation rate of $\mathrm{NOx}$ in tail gas by photocatalytic road pavement has been achieved by $10 \%$ to $30 \%$. Due to the influence of illumination, there is no relevant report on the practical application in highway tunnels yet. Furthermore, according to comprehensive literature analysis, most of researches on photocatalytic materials applied to pavement, facilities, buildings, walls

\footnotetext{
"Corresponding author's e-mail: 44198127@qq.com
} 
of highway system mainly are still on the laboratory research stage, with different product performance and stability, great differences in process equipment, limited engineering application scope of products, insufficient construction technology experience, and without unified and standardized testing and evaluation indicators, standards and methods at present, which objectively affected the continuous research \& development and large-scale engineering application of such products.

The above analysis shows that the research and engineering application of titanium dioxide and other photocatalytic materials are in line with the green, ecological and sustainable development concepts of the world and China today, because as a food-grade safety material, the photocatalysis process by nano- $\mathrm{TiO} 2$ is based on inexhaustible clean energy - light energy, and titanium dioxide as a photocatalytic material can degrade most organic and inorganic pollutants, and can achieve comprehensive pollutant degradation by itself However, due to the titanium dioxide itself, as well as its application in practical engineering, the photocatalytic materials is still in the laboratory R \& D stage or only used in small scene.

\section{Application scene analysis}

\section{(1) Tunnel lighting luminaries}

With the development of photocatalysis technology, $\mathrm{TiO} 2$ photocatalysis has been applied to treat automobile exhaust in tunnel. At present, $\mathrm{TiO} 2$ has been used as a photocatalysis coating on the inner wall of tunnel and lamp shade glass to remove pollutants in tunnel. Applying $\mathrm{TiO} 2$ photocatalysis coating on the lamp shade glass and the inner wall of tunnel can degrade the automobile exhaust, so as to ensure the cleanness of lamp shade glass and reduce the air pollution in tunnel.

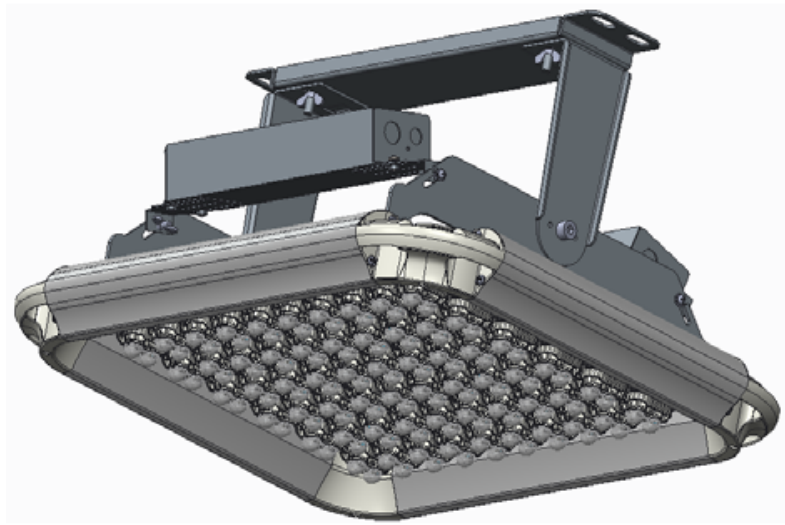

Figure 2 Application on tunnel lighting luminaries

(2) Tunnel pavement

Due to the different roughness, structure and elements of different pavement in tunnel, it is very important to study whether nano-TiO2 can be adsorbed tightly on the surface of these materials without affecting its photocatalytic performance of and the integrity and beauty of the target material surface. At present, there are two ways to apply $\mathrm{TiO} 2$ photocatalyst materials to the road surface. One is to make a sol coating containing titanium dioxide and spray it directly on the road surface; the other is to add it to the asphalt as a modifier and mix it with the asphalt mixture to pave the road directly.

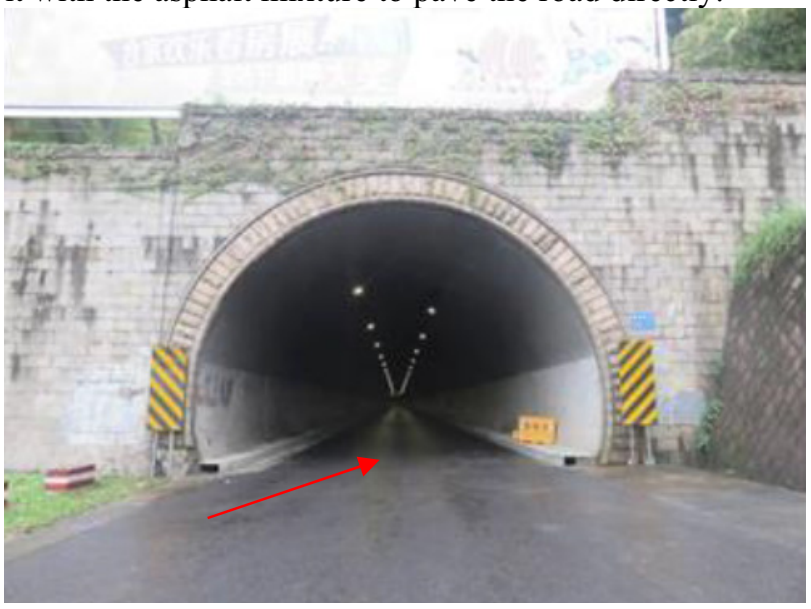

Figure3 Application on tunnel pavement

(3) Application on tunnel wall

Directly spray $\mathrm{TiO} 2$ photocatalytic material on the tunnel wall surface. Combined with the functional requirements of sound absorption and fire prevention, develop the materials with synergistic functions for exhaust gas purification, sound absorption, and noise reduction in highway tunnel to achieve the prevention of vehicle exhaust gas, chemical atmospheric pollution and tunnel noise, and the biodegradation of environmental pollution.

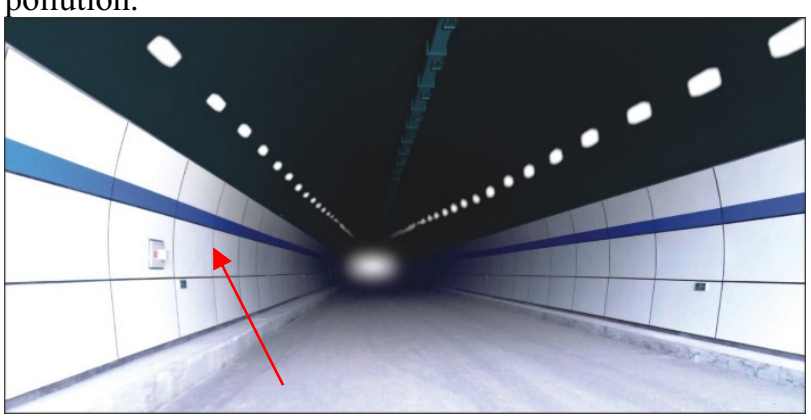

Figure 4 Application on tunnel wall

\section{Preparation of Tio2 aerosol products}

(1) Preparation principle of sol-gel method

At present, the methods to synthesize $\mathrm{TiO} 2$ powders mainly include liquid phase method and gas phase method. Compared with other methods, the sol-gel method has great advantage such as easy control of reaction conditions, narrow grain size distribution, controlling crystal shape according to calcination temperature, improving the utilization of visible light and increasing photocatalytic activity. The main factors affecting the preparation of samples by sol-gel method include concentration of reactants, temperature of reaction solution, amount of water added, reaction drop acceleration, $\mathrm{pH}$ of reactant solution, aging environment, etc.

(2) Process Routing of Experiment

According to the principle of sol-gel preparation, the specific technological process for the preparation of $\mathrm{TiO} 2$ dioxide aerosol products includes the following nine aspects: (1) hydrolysis of $\mathrm{TiCl}$;(2) add alkali 
precipitation;(3) glue solution;(4) control of $\mathrm{pH}$ value;(5) TiO2 titanium composite preparation;(6) Temperature control;(7) Visible photosensitization technology;(8) Product filtration and purification;(9) Product packaging.

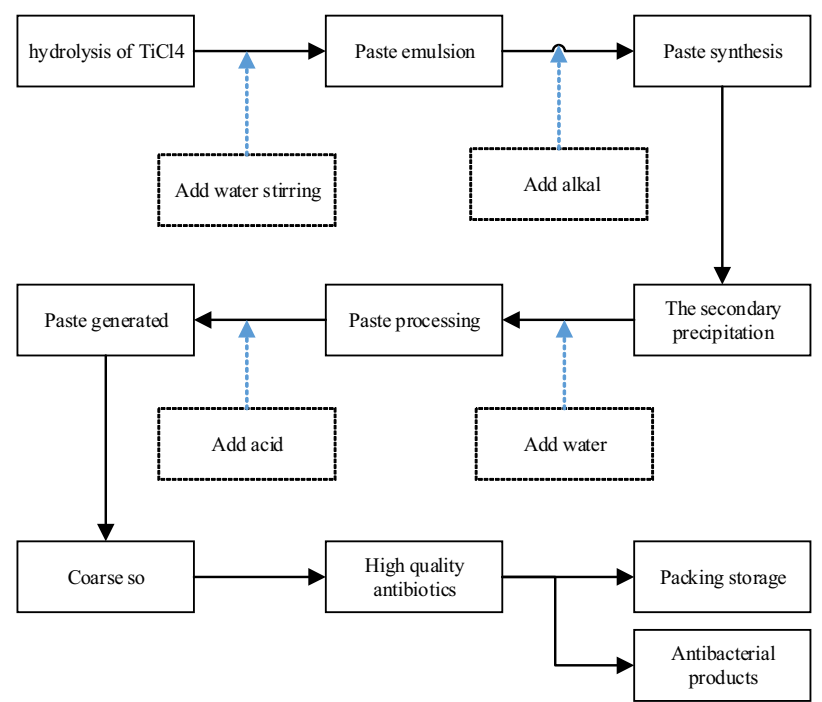

Figure 5 process flow diagram

\section{Exhaust degradation efficiency}

Under the simulated tunnel light environment, based on test results of catalytic decomposition of automobile exhaust, the exhaust degradation efficiency of asphalt mixtures with different $\mathrm{TiO}_{2}$ contents under ordinary light is detected to understand the influence of $\mathrm{TiO}_{2}$ photocatalytic asphalt pavement on automobile exhaust purification efficiency.

In this experiment, the lamp with simulated sunlight is used, and the light source emitted by the lamp can effectively simulate the ultraviolet radiation in the sunlight. In addition, considering the influence of low temperature on the degradation of automobile exhaust by nano- $\mathrm{TiO}_{2}$, the selected light source's temperature should not be too high when shining, so OSRAM $300 \mathrm{~W}$ is used as the lamp with simulated sunlight.

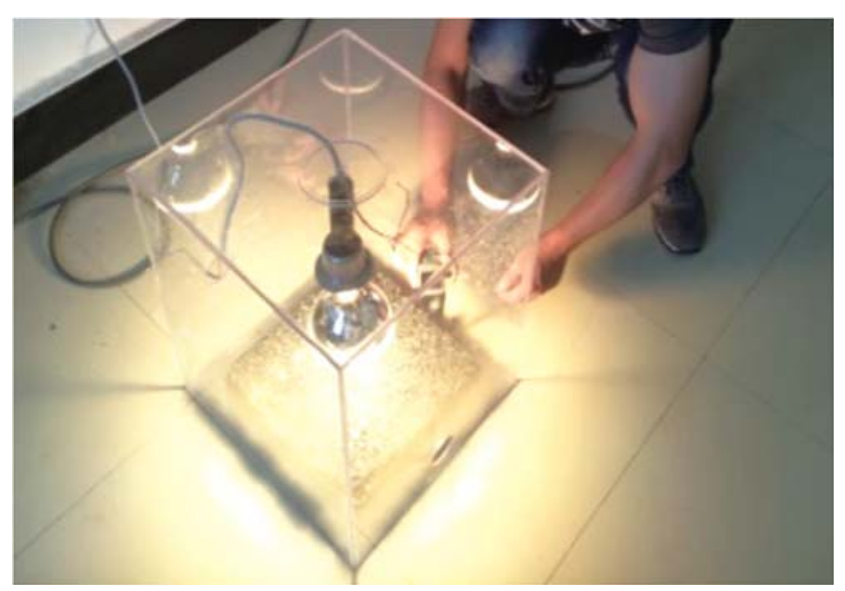

Figure 6 The degenerating materials' testing
The experimental steps include collecting the water samples of the degraded product of tail gas, detecting the concentration of nitrate nitrogen in the water samples, and calculating the degradation rate of nitrogen oxides. Samples are collected by plate sampling method. The executive standard is Ion Chromatography for the Determination of Inorganic Anions $\left(\mathrm{F}^{-}, \mathrm{Cl}^{-}, \mathrm{NO}_{2}^{-}, \mathrm{Br}^{-}\right.$, $\left.\mathrm{NO}_{3}{ }^{-}, \mathrm{PO}_{4}{ }^{3-}, \mathrm{SO}_{3}{ }^{2-}, \mathrm{SO}_{4}{ }^{2-}\right)(\mathrm{HJ} 84-2016)$.

(2) Sampling method

Specific steps are as follows: the site sampling should be conducted at 14:00 15:00 on the sampling day, and the traffic flow and weather conditions at the section should be recorded at the same time. Several $500 \mathrm{ml}$ and $100 \mathrm{ml}$ sampling bottles, $1.5 \mathrm{~L}$ gathering barrel, ultra-pure water, water scoops and other instruments should be prepared. During sampling, place the gathering barrel under the asphalt sample plate, and then repeatedly flush the samples with $4 \mathrm{~L}$ ultra-pure water, and ensure that the water flows into the gathering barrel. Flush from left to right, and from top to bottom. Each sample plate should be flushed about $5 \mathrm{~min}$. Separate gathering barrel and sampling bottle should be used for each asphalt plate without mixing. After flushing, the liquid in the gathering barrel should be filled into a $500 \mathrm{ml}$ sampling bottle, and then numbered and sealed away from light for preservation. After sampling, according to the requirement of Ion Chromatography for the Determination of Inorganic Anions $\left(\mathrm{F}^{-}, \mathrm{Cl}^{-}, \mathrm{NO}_{2}^{-}, \mathrm{Br}^{-}\right.$, $\left.\mathrm{NO}_{3}{ }^{-}, \mathrm{PO}_{4}{ }^{3-}, \mathrm{SO}_{3}{ }^{2-}, \mathrm{SO}_{4}{ }^{2-}\right)(\mathrm{HJ}$ 84-2016), entrust a third party to detect the concentration of nitrate. The sampling period can be set according to the actual situation, usually the nitrate content accumulated on the sampling plate in a week. According to the nitrate concentration and traffic flow, the nitrogen oxide degradation rate is calculated.

(3) Data analysis

Gaseous nitrogen oxides are converted into nitrate by photocatalysis, and the degradation rate is calculated according to the concentration difference of nitrogen oxides before and after the conversion. The calculation formula is as follows:

$$
K=\frac{\text { Average daily degradation of NOx }}{\text { Average daily emission of NOx }} \times 100 \%
$$

Where: $K \longrightarrow$ degradation rate, $\%$;

The test results show that the content of nitrite produced by sample 4 is relatively high, and the degradation effect of tail gas is good, mainly because the surface area of sample 4 contacting with air is relatively larger than other samples. 
Table 1 Nitrite product data

\begin{tabular}{c|c|c|c|c}
\hline Time & $\begin{array}{c}\text { Sample 1 (nitrite } \\
\mathrm{mg} / \mathrm{l})\end{array}$ & $\begin{array}{c}\text { Sample 2 (nitrite } \\
\mathrm{mg} / \mathrm{l})\end{array}$ & $\begin{array}{c}\text { Sample 3 (nitrite } \\
\mathrm{mg} / \mathrm{l})\end{array}$ & $\begin{array}{c}\text { Sample 4 (nitrite } \\
\mathrm{mg} / \mathrm{l})\end{array}$ \\
\hline 0 & 0 & 0 & 0 & 0 \\
\hline $24 \mathrm{~h}$ & 1.11 & 1.25 & 1.26 & 1.31 \\
\hline
\end{tabular}

\section{Conclusions and suggestions}

This paper is applied to the exhaust purification materials for highway tunnels, which can achieve the prevention of vehicle exhaust gas, chemical atmospheric pollution and tunnel noise, and the biodegradation of environmental pollution, improve the overall autonomous purification ability of the station area, effectively protect the health of drivers and passengers and station staff, and effectively degrade oily pollutants in the highway environment in a green and clean way, can also optimize the highway driving environment and improve the comfort and safety of highway driving, promote the creation and application of advanced engineering materials in highway industry, promote the development of self-cleaning highway infrastructure, practice green transportation and the green ecological benefits of highway construction, and has extremely high social and environmental benefits.

\section{References}

1. He Kebin, Yang Fumo, Ma Yongliang, et al. (2001) The Characteristics of PM2. 5 in Beijing, China. Atmospheric Environment, 35(29): 49594970

2. Cen K, Neumann T, Norra S, et al. (2004) Land Use-related Chemical Composition of Street Sediments in Beijing. Environmental Science and Pollution Research, 11 (2): 73 - 83.

3. Song X H, Polissar A V, Hopke P K. (2001) Sources of Fine Particle Composition in the Northeastern US. Atmospheric Environment, 35: 5227-5286.

4. Hyv rinen A P, Kolmonen P, Kerminen V M, et al. (2001) Aerosol Black Carbon at Five Background Measurement Sites over. Atmospheric Environment, 45:4042-4050

5. Hoffmann V, Knab M, Appel E. (1999) Magnetic Susceptibility Mapping of Roadside Pollution. J Geochem Expl, 66: 313-326

6. Li Li, Wang Wu, Feng Jialiang, et al. (2010) Composition, Source, Mass Closure of PM2. 5 Aerosols for Four Forests in Eastern China. Journal of Environmental Sciences, 22(3): 405412 